\title{
The priority effect: Test effects on negative transfer and control lists
}

\author{
DONALD ROBBINS and JAMES R. IRVIN \\ Emory University, Atlanta, Georgia 30322
}

\begin{abstract}
A study is reported investigating the "priority effect." This effect refers to the finding of superior List 1 recall over List 2 on a MMFR test when the two lists conform to an A-B, A-D procedure. The result that the priority effect occurs only when no immediate test is given is confirmed. In addition, when AB-CD lists are used, no such effect is found. It is suggested that the assumption that the priority effect results from a process operating at the list level needs to be augmented based on these findings.
\end{abstract}

Typically, performance on a MMFR test after learning two lists, denoted as List A-B then List A-D, reveals greater recall of second-list in contrast to first-list responses (e.g., Keppel, 1968). Recently, Tulving and Watkins (1974) reported a series of studies in which higher first-list than second-list recall on a MMFR test was found. They termed this finding the "priority effect." Their results indicated that the priority effect occurs when there is no immediate test after List 1. Further, they found that failure to test List 1 resulted in a dramatic reduction on an immediate recall test after second-list presentation of List 2 responses. This negative transfer subsequently reappears on a MMFR test, resulting in the "pricrity effect." Tulving and Watkins cite two unpublished studies in which higher first-list than second-list recall was found on a MMFR test (the priority effect) when there were no immediate tests after presentation of the A-B and A-D lists. The reverse was found when there were immediate tests, i.e., higher recall of second-list than first-list responses. It should be noted that when only one trial is given on both lists the latter result is not always found. For example, in Tulving and Watkins (1974, Experiment 1), although the priority effect was found on MMFR tests for conditions in which there were no immediate first-list tests, when there were immediate tests, the MMFR data indicated that List 1 responses were numerically superior to those of List 2. This is contrary to the unpublished and published data they cite indicating that immediate tests resulted in higher second-list than first-list responses on a MMFR test. Thus, one trial on each list may not always yield the general finding of greater recall of second-list in contrast to first-list responses (e.g., Keppel, 1968). The critical result is, however, that of an interaction between immediate test condition (test or no test) and response recalled (List 1 or 2).

This research was supported in part by a grant from the Graduate School of Arts and Sciences of Emory University, and in part by Grant 5 T01 HD 00208 from the National Institute of Child Health and Development. Reprint requests should be sent to D. Robbins, Department of Psychology, Emory University, Atlanta, Georgia 30322.
Tulving and Watkins (1974) also cited an unpublished doctoral dissertation by Malis, who found in addition to the priority effect, that for an A-B (List 1), C-D (List 2) condition, List 2 responses were always higher on a MMFR test whether or not there was an immediate test after each list. Tulving and Watkins did not include any A-B, C-D conditions in their studies. They concluded that the priority effect does not arise from pairspecific effects but rather from a general list effect, since in their Experiment 2 they failed to find a priority effect with a within-subject design.

In the experiment to be reported here, a factorial combination of immediate test condition (test or no test) and type of lists (A-B, A-D or A-B, C-D) was used. A filler task was used such that the presentation of lists was at the same time for each condition, and while some subjects were being tested the no-test subjects were engaged in a filler task. In this way, input orders and retention intervals were perfectly controlled.

\section{Subjects}

Thirty-two introductory psychology students partially fulfilled a course requirement by participating in the experiment.

\section{Materials}

A large pool of six-letter English words (650) was selected from the Thorndike and Lorge (1944) word frequency count, with the restriction that each word have a frequency of A or AA. The words were assigned to pairs randomly with the following restrictions: (1) words that had an obvious meaningful association were not paired; (2) words that began with the same letter of the alphabet were not paired; and (3) for the A-B, A-D conditions, the words for $B$ and $D$ could not begin with the same letter. Each study pair and each test word (stimulus word only) was typed on a $2 \times 2$ in. slide $(.51 \times .51 \mathrm{~cm})$ in capital letters.

\section{Design and Procedure}

A between-subject design was used with four groups ( $n=8$ /group) which represented a factorial combination of immediate test condition (test or filler) and paired-associate list type (A-B, A-D or A-B, C-D). For ABAD-test and ABADfiller, $12 \mathrm{~A}-\mathrm{B}, \mathrm{A}-\mathrm{D}$ sequences were constructed, with the A-B pairs constituting List 1 and the A-D pairs constituting List 2. Each subject in each group had a different sequence, and the specific word pairs used for A-B and A-D were reversed for half 
of the subjects. For ABCD-test and ABCD-filler 24 A-B pairs were used. Half were assigned to List 1 and coincided with the same word pairs for the ABAD subjects, and half were designated C-D pairs and were similarly yoked; i.e., the A-D term was replaced with a C-D term, and assigned to List 2 . As a result, first- and second-list responses were counterbalanced for the ABAD conditions and the word pairs representing the ABCD conditions were yoked to them. The filler task consisted of crossing out all of the threes and sevens on a sheet of random numbers for $1 \mathrm{~min}$. This was done to equate all conditions on the amount of time between List 1 and List 2, the amount of time between List 2 and the MMFR test, and the total time taken to complete a condition.

Study of a list consisted of presentation of each pair in the list for $5 \mathrm{sec}$. The subjects were not told before studying a list whether or not they would be tested immediately or after presentation of both lists. For the test immediately after List 1 and List 2, the subjects were given a numbered answer sheet and instructed to write down the response word for each stimulus word. Each stimulus word was then presented in a random order for $5 \mathrm{sec}$. For the MMFR test, the subject was provided with a sheet that contained all of the stimulus terms and given 5 min to write down as many response words next to the appropriate stimulus term as possible.

The subjects were initially given a practice test of six A-B pairs followed by a test trial. The experimental condition followed. Subjects were tested in groups of one to five.

\section{RESULTS AND DISCUSSION}

In Table 1 is shown the mean proportion correctly recalled on the immediate and MMFR test. On the immediate test no differences between recall of first- and second-list responses were found for both the ABAD and $\mathrm{ABCD}$ lists, Fs $<1$. However, more responses were recalled for the lists given immediate tests in contrast to those given the filler task, $F(1,28)=9.22$, p $<.01$, $\mathrm{MS}_{\mathrm{e}}=8.30$. Table 1 also shows the results of the MMFR test. For the test condition, there was no difference be-

Table 1

Mean Proportion Correctly Recalled on the Immediate Test and the MMFR Test

\begin{tabular}{ccccccc}
\hline & \multicolumn{3}{c}{ Immediate } & & \multicolumn{2}{c}{ MMFR } \\
\cline { 2 - 3 } \cline { 6 - 7 } Types & Test Condition & List 1 & List 2 & & List 1 & List 2 \\
\hline ABAD & Test & .281 & .354 & & .240 & .323 \\
ABCD & Test & .531 & .500 & & .448 & .490 \\
ABAD & Filler & & & & .260 & .167 \\
ABCD & Filler & & & & .177 & .250 \\
\hline
\end{tabular}

tween first- and second-list responses for both the $\mathrm{ABCD}$ condition and the ABAD condition, Fs $<1$. For the filler conditions, more second- than first-list responses were made for the $A B C D$ condition, while the reverse was the case for the ABAD condition. This was confirmed by a statistically significant List Type by Response interaction for the filler condition, $\mathrm{F}(1,28)=7.96, \mathrm{p}<.01, \mathrm{MS}_{\mathrm{e}}=2.01$. The latter finding replicates the Tulving and Watkins (1974) report of a priority effect when List 1 is not given an immediate test.

The results of the present study replicate and extend the Tulving and Watkins (1974) finding of a priority effect, i.e., greater recall of first-list (A-B) in contrast to second-list (A-D) responses. The superiority in recall of List 1 over List 2 responses does not appear to occur with two unrelated lists, A-B and C-D. Thus, if the priority effect results from a process operating at the list level, as Tulving and Watkins (1974) assume, similar (or identical) stimuli on the two lists may be necessary, since it does not occur with A-B, C-D lists.

Finally, it should be noted that, as shown in Table 1, comparison of the $\mathrm{AB}-\mathrm{AD}$ lists and their respective AB-CD controls on the MMFR test revealed both retroactive and proactive interference when an immediate test was given and retroactive facilitation (e.g., Robbins \& Bray, 1974) and proactive interference when no immediate test was given.

\section{REFERENCES}

KEPPEL, G. Retroactive and proactive inhibition. In T. $R$. Dixon \& D. L. Horton (Eds.), Verbal behavior and general behavior theory. Englewood Cliffs, New Jersey: Prentice Hall, 1968.

Robrins, D., \& Bray, J. F. The spacing effect and the A-B, A-C paradigm. Journal of Experimental Psychology, 1974, 103, 420-425.

THORNDIKE, E. L., \& LORGE, I. The teacher's wordbook of 30,000 words. New York: Teachers College, Columbia University, 1944.

Tulving, E., \& Watkins, M. J. On negative transfer: Effects of testing one list on the recall of another. Journal of Verbal Learning and Verbal Behavior, 1974, 13, 181-193.

(Received for publication May 13, 1976.) 